
granic, języków i kultur. Slavia Meridionalis, 21, Article 2402. https://doi.org/10.11649/sm.2402

\title{
Halina Kurek
}

Uniwersytet Jagielloński

https://orcid.org/0000-0002-9578-7293

\section{Polskie miasta i wsie XXI wieku. Zacieranie się granic, języków i kultur}

Zarówno miasto, jak i wieś definiować można z dwu perspektyw: 1) geograficznej, przestrzennej oraz 2) społecznej (Sawaniewska-Mochowa \& Moch, 2001, s. 270).

Terytorialny punkt widzenia określa wieś jako „jednostkę osadniczą o zwartej, skupionej lub rozproszonej zabudowie i istniejących funkcjach rolniczych lub związanych z nimi usługowych albo turystycznych, nieposiadającą praw miejskich lub statusu miasta” („Ustawa o urzędowych nazwach miejscowości i obiektów fizjograficznych”, 2003). Miasto z kolei definiuje jako „duży obszar intensywnie i planowo zabudowany, podlegający odrębnej administracji, będący skupiskiem ludności wykonującej zawody nierolnicze" (Szymczak, 1979, s. 152). Realna przestrzeń geograficzna miast i wsi pozwala je zatem wyodrębnić administracyjnie i precyzyjnie określić ich granice.

Obie jednostki urbanistyczne jako osady zamieszkane przez człowieka są też określonymi typami przestrzeni społecznej z właściwymi sobie systemami

This work was supported by the Polish Ministry of Education and Science.

Competing interests: no competing interests have been declared.

Publisher: Institute of Slavic Studies, Polish Academy of Sciences.

This is an Open Access article distributed under the terms of the Creative Commons Attribution 3.0 PL License (creativecommons.org/licenses/by/3.0/pl/), which permits redistribution, commercial and non-commercial, provided that the article is properly cited. () The Author(s) 2021. 
kulturowymi, nakładającymi się na owe realne, miejskie lub wiejskie przestrzenie topograficzne (Handke, 1995, s. 20; szerzej na ten temat zob. Kurek, 2019).

Cechą miejskich i wiejskich zespołów kulturowych są: odrębne, typowe dlań „wyobrażenia i zachowania, swoisty styl życia i system wartości” (Kopczyńska-Jaworska, 1991, s. 5) oraz różny system językowy: polszczyzna ogólna i gwara.

Do połowy XX wieku polskie miasta jako organizmy gospodarcze i zbiorowości charakteryzujące się bardzo zróżnicowaną strukturą zawodową i społeczną ludności oddzielały od monolitycznej, tradycyjnej wsi zarówno granice administracyjne, jak i, nakładające się nań, wyraźne granice językowe. „Wspólnoty ludzkie do kształtowania własnych przestrzeni społecznych [miejskich i wiejskich - uzup. H.K.] [...] wykorzystywały [...] [bowiem - uzup. H.K.] w znacznym stopniu tworzywo językowe" (Handke, 1995, s. 20). Od czasów powojennych na skutek różnorodnych czynników rozpoczął się jednak w Polsce stopniowy proces zacierania się owych granic, a na przełomie wieków XX i XXI opisywane zjawisko uległo gwałtownemu, wręcz ,anormalnemu” przyspieszeniu.

Po II wojnie światowej w wyniku przemian administracyjnych najpierw zaczęły ulegać zmianom geograficzne granice miast. Wielkie miasta wchłaniały bowiem stopniowo okoliczne wsie położone o kilkanaście, a nawet o kilkadziesiąt kilometrów od wielkomiejskiego centrum i przekształcały je w swoje dzielnice (Fleszar, 1978, ss. 158-159) ${ }^{1}$. Zmiana granic administracyjnych między miastem a wsią początkowo nie powodowała zacierania się granic językowo-kulturowych, ponieważ na przyłączonym obszarze przeobrażenia w sposobie językowego zachowania się mieszkańców dołączonych miejscowości zachodziły na tyle wolno, że przez wiele kolejnych lat nadal obowiązywały tu językowo-kulturowe normy typowe dla społeczeństwa wiejskiego. Ta silnie zintegrowana, na wpół rolnicza społeczność, na skutek narastającego pozarolnego zatrudnienia, a co za tym idzie, wytwarzania się nowych więzi społecznych, ulegała jednak stopniowemu rozpadowi, co w rezultacie oznaczało początek procesu zacierania się granic językowo-kulturowych (Rajman, 1997, s. 98).

Drugim ważnym zjawiskiem okresu powojennego były migracje mieszkańców wsi do miast. Przekroczenie granicy geograficznej i jednocześnie językowo-kulturowej u większości osiedleńców ze wsi uruchomiło proces świadomego odcinania się od języka i kultury macierzystego środowiska, co,

1 Dla porównania w 1986 roku do Nowej Huty przyłączono dwie wsie o typowo rolniczym charakterze - Węgrzynowice i Wróżenice. W Węgrzynowicach użytki rolne stanowiły 96\% powierzchni, a we Wróżenicach - 97\% (Luchter, 2012, s. 22). 
w połączeniu ze wzrostem poziomu ich wykształcenia, rozpoczęło w tej grupie proces zacierania się granic kulturowych i językowych. Nie bez znaczenia było tu doświadczanie swoistego deficytu tożsamości: dawna bowiem została odrzucona, a nowa - jeszcze nie nabyta (Kowalikowa, 1995, s. 76).

O kierunku zachodzących zmian przede wszystkim zdecydowały siła i prestiż pozostających w kontakcie systemów językowo-kulturowych. „Każdy język - pisał Władysław Miodunka - [i szerzej, każda kultura - uzup. H.K.] ma określoną moc w stosunku do innych języków, zktórymi może wchodzić w kontakt" (Miodunka, 2003, s. 13). Owa moc zależy w dużej mierze od jakości i siły wartości kulturowych utrwalonych w języku, bowiem to one decydują o skali oddziaływania systemu językowo-kulturowego pozostającego w kontakcie (Kurek, 2019, s. 211).

Nie ulega wątpliwości, że polszczyzna ogólna, stanowiąca podstawowy składnik miejskiego systemu kulturowego, ma większą moc, aniżeli gwara będąca wytworem wiejskiego typu kultury. W związku z tym ekspansywny, bo silniejszy typ kultury obowiązujący w miastach narzucał swoje najbardziej wyraziste cechy osiedleńcom ze wsi, powodując w ich świadomości stopniowe zacieranie się granic językowo-kulturowych.

Przekraczanie miejsko-wiejskich granic geograficznych obserwuje się również obecnie. Na przełomie wieków XX i XXI w Polsce zaczęło się bowiem nasilać zjawisko przeprowadzania się na wieś mieszkańców dużych aglomeracji miejskich. Zanotowano je między innymi w Małopolsce, gdzie w latach 2005-2018 liczba mieszkańców wsi, w znacznym stopniu $\mathrm{z}$ tego powodu, wzrosła z 1,6 do 1,8 mln osób (Bartuś, 2018, s. 6). W rezultacie od przełomu wieków XX i XXI na polskiej wsi, a zwłaszcza w strefach podmiejskich, tworzą się „enklawy miejskiej klasy średniej, często wyobcowanej z tradycyjnej lokalnej społeczności” (Bartuś, 2018, s. 6). Przekraczanie miejsko-wiejskich granic geograficznych i osiedlanie się na wsi przybyszów z miasta w tym wypadku nie oznacza jednak przekraczania granic językowo-kulturowych, ponieważ polszczyzna ogólna i, szerzej, miejski typ kultury są przez Polaków wyżej społecznie wartościowane aniżeli kultura ludowa i reprezentująca ją gwara. Można przypuszczać, że to raczej przybysze z miasta stopniowo będą oddziaływać na kulturę i język wiejskiej wspólnoty, co niewątpliwie będzie wpływać na zacieranie się granic miejskiego i wiejskiego systemu językowo-kulturowego.

$\mathrm{W}$ drugiej połowie XX wieku proces zacierania się granic językowych i kulturowych pomiędzy wsią a miastem nie wymagał już przekraczania granic geo- 
graficznych i osiedlania się mieszkańców wsi poza macierzystą miejscowością. Na skutek przemian społeczno-ekonomicznych, gospodarczych i politycznych, jakie dokonywały się po wojnie na wiejskim obszarze języka i kultury, a zwłaszcza dzięki powszechnemu dostępowi do szkół oraz środkom masowego przekazu radiu, telewizji i prasie, wzrosła świadomość mocy języka ogólnopolskiego i miejskiego typu kultury, a co za tym idzie, na wsi rozpoczął się proces przechodzenia z systemów dialektalnych na system polszczyzny ogólnej.

Owo przechodzenie, skutkujące zacieraniem się granic językowo-kulturowych, nie polegało jednak na prostym zamienianiu wariantów gwarowych na standardowe w każdym typie kontaktu językowego. Proces rozpoczął się bowiem w oficjalnej sytuacji komunikacyjnej, a jego pierwszym świadectwem było eliminowanie z wypowiedzi nadawców uświadamianych cech kodu gwarowego, pozostawianie natomiast tych dialektyzmów, które nie były dostrzegane przez wiejską zbiorowość. Usuwanie zjawisk uświadamianych dokonywało się też zwykle w sposób ewolucyjny. W książce pt. Metodologia socjolingwistycznego badania fonetyki języka mówionego środowisk wiejskich (na przykładzie kilku wsi Beskidu Niskiego) opublikowanej w roku 1990 napisałam, że przy przełączaniu kodu gwarowego na ogólnopolski bardzo często pojawiały się nowe jakości, czyli tzw. warianty pośrednie, które, nie były już typowe dla danej gwary, ale nie można ich było jeszcze uznać za realizacje standardowe (Kurek, 1990, s. 162).

Podobne stwierdzenie znajdziemy w artykule Zuzanny Topolińskiej, zatytułowanym Charakterystyka i dynamika językowych procesów integracyjnych $w$ powojennej Polsce wydanym również w roku 1990, która napisała, że na wsi powstaje system:

[...] o ogromnej skali idiolektalnej wariancji, którą daje się określić przede wszystkim negatywnie, tj. jako zbiór podzbiorów cech gramatycznych nieidentycznych ani z żadnym dialektem, ani z językiem ogólnym. Trzeba przy tym pamiętać, że nie jest to prosta mieszanka cech różnych systemów dialektalnych, gdyż reinterpretacja reguł języka ogólnego w kategoriach przyzwyczajeń, jakie utrwaliły systemy dialektalne, stwarza „trzecią jakość” jako jedną z cech definicyjnych [substandardu - uzup. H.K.] (Topolińska, 1990, s. 33).

Świadectwem ewolucyjnego zacierania się granic językowo-kulturowych w zbiorowościach wiejskich, a także w grupach osiedleńców ze wsi, zamieszkałych w miastach, jest posługiwanie się tzw. polszczyzną substandardową. W miastach jest to tzw. substandard miejski, bliższy językowi ogólnopolskiemu, na wsiach - zbliżony do gwary substandard wiejski. Obecnie oba wymienione typy oznaczają jednak „pułap społeczny możliwości językowych swego nosiciela 
na danym etapie" (Topolińska, 1990, s. 34), czyli pułap unifikacji miejskich i wiejskich systemów językowych i kulturowych.

Zjawisko zacierania się granic językowo-kulturowych na wsi i w mieście gwałtownie przybrało na sile na przełomie wieków XX i XXI. W roku 1989 Polska weszła w okres transformacji ustrojowej, społecznej, ekonomicznej, gospodarczej i politycznej, a 1 maja 2004 roku stała się jednym z krajów Unii Europejskiej, co oznaczało automatyczne włączenie polskiego społeczeństwa w obręb globalnej, medialnej i konsumpcyjnej kultury świata zachodniego (Ożóg, 2001, s. 196). Podobnie jak inne języki słowiańskie procesowi globalizacji uległa także polszczyzna.

Globalizacja, pisał Stanisław Gajda, to „wiązka zachodzących dziś w świecie procesów ekonomicznych, politycznych i kulturowych, w których wyniku narody świata zostają włączone $\mathrm{w}$ jedno globalne społeczeństwo, w jeden wspólny świat" (Gajda, 2007, s. 16). W odniesieniu do kultury globalizacja oznacza zmniejszenie barier kulturowych pomiędzy poszczególnymi krajami, skutkujące przenikaniem i mieszaniem się elementów różnych kultur, co powoduje zacieranie się ich granic, a w przyszłości może doprowadzić do unifikacji kontaktujących się ze sobą systemów kulturowych.

Każda kultura przejawia się poprzez język, który jest jej wytworem oraz podstawowym składnikiem. Język kultury globalizującej musi być kodem międzynarodowym i mieć dużą liczbę użytkowników. W związku z tym do przemian w kontekście globalnym wykorzystuje się wyłącznie wielkie języki. $\mathrm{Na}$ Zachodzie należy do nich język angielski, który we wszystkich krajach europejskich preferowany jest w nauce szkolnej i pozaszkolnej jako język obcy i którym w Europie, oprócz krajów anglosaskich, posługuje się aż 90\% Szwedów i Holendrów (Gajda, 2007, s. 17). Po II wojnie światowej Anglia i Stany Zjednoczone znacznie też zwiększyły nakłady na doskonalenie metod nauczania języka angielskiego jako obcego (Witalisz, 2016, s. 30).

Angielsko-amerykański system językowo-kulturowy przełomu wieków to typ ekspansywnej postmodernistycznej kultury informatycznej, medialnej i konsumpcyjnej, która za pomocą języka silnie oddziałuje na kontaktujące się z nią zespoły językowo-kulturowe, posiadające mniejszą niż ona liczbę użytkowników. Ów kontakt ma miejsce w sieci, czyli w rzeczywistości wirtualnej, w której człowiek jednocześnie może zmienić „społeczność, kulturę i [...] życie społeczne” (Zeler \& Żydek-Bednarczuk, 2009, s. 89), gdzie „na styku światów realnego i wirtualnego rodzi się nowa kultura, w znacznym stopniu implikowana przez medium" (Gołębiewski, 2008, s. 13). 
Na przełomie wieków XX i XXI polska społeczność miast i wsi, poprzez internetowy kontakt z zachodnim (amerykańskim) systemem językowo-kulturowym, stała się częścią nowej wspólnoty - społeczeństwa informacyjnego. Wielu Polaków entuzjastycznie przyjęło kulturowe propozycje Zachodu, widząc w nich „walor nowości (nowoczesności) i wolności” (Ożóg, 2014, s. 18). W konsekwencji w przestrzeni wirtualnej rozpoczął się proces zacierania się granic pomiędzy językiem i kulturą świata zachodniego a językowo-kulturowymi systemami polskich społeczności miast i wsi.

Język angielski, pełniąc funkcję globalizatora, wpływa na wszystkie języki świata, w tym również na polszczyznę. W grupie języków obcych, którymi posługują się Polacy, zajmuje bardzo wysoką pozycję. Jest pierwszym i najważniejszym obcym językiem, a „w komunikacji średniego, młodszego i najmłodszego pokolenia [Polaków - uzup. H.K.] [...] staje się niejednokrotnie językiem drugim" (Dubisz, 2011, s. 240). Stąd w niektórych opracowaniach językoznawczych pisze się „o swoistej polifonii językowej polsko-angielskiej, bilingwizmie polsko-angielskim" (Dubisz, 2011, s. 240).

Z badań Elżbiety Mańczak-Wohlfeld, przeprowadzonych w grupie 59 anglistów z Instytutu Filologii Angielskiej Uniwersytetu Jagiellońskiego i z Nauczycielskiego Kolegium Języków Obcych (sekcja angielska) przy Wydziale Filologicznym UJ oraz 59 polonistów z Wydziału Polonistyki UJ oraz Podhalańskiej Państwowej Wyższej Szkoły Zawodowej w Nowym Targu, wynika, że młodzi Polacy akceptują wprowadzanie anglicyzmów do języka polskiego, argumentując, że:

1. [...] są krótsze, brzmią lepiej, dobitniej (?), są ciekawsze (?), bardziej trendy.

2. Trafniej określają przedmiot, zjawisko itp. niż polskie odpowiedniki.

3. Jest prościej przejąć zapożyczenie aniżeli tworzyć polski odpowiednik lub przetłumaczyć wyraz $\mathrm{z}$ angielskiego.

4. Wzbogacają język polski.

5. Ułatwiają funkcjonowanie polszczyzny.

6. Umiędzynarodawiają i unowocześniają język polski.

7. Ułatwiają komunikację międzynarodową i międzykulturową.

8. Powodują, iż polski staje się ,językiem bardziej uniwersalnym”.

9. Upraszczają naukę języka angielskiego (Mańczak-Wohlfeld, 2010, s. 219).

Skutkiem procesów globalizacyjnych związanych z wpływem języka angielskiego na polszczyznę było pojawienie się nowych zjawisk językowych. Owe zjawiska widoczne są na wszystkich płaszczyznach języka: leksykalnej 
i słowotwórczej (zapożyczenia właściwe, kalki semantyczne, kalki strukturalno-semantyczne, półkalki - słownictwo i frazeologia), gramatycznej (zmiany składniowe, fleksyjne), fonetycznej i ortograficznej oraz pragmatycznej (Dubisz, 2011; Mańczak-Wohlfeld, 2010, 2012, 2013; Mańczak-Wohlfeld \& Witalisz, 2016; Markowski, 2008, ss. 144-147; Piotrowicz \& Witaszek-Samborska, 2016, s. 155; Witalisz, 2016, ss. 21-25 i in.). Ich „anormalne” nagromadzenie spowodowało, że na przełomie wieków XX i XXI rozpoczął się w Polsce proces „kształtowania się nowego wzorca językowego, odległego od kanonów kulturalnej polszczyzny drugiej połowy XX w." (Markowski, 2008, s. 144).

Silny wpływ języka angielskiego wcale nie musi być zagrożeniem dla polszczyzny ogólnej, przeciwnie - może stać się inspiracją i stymulatorem przeobrażeń językowych. W efekcie długotrwałego oddziaływania doprowadzi jednak w polskiej społeczności do określonych zmian wartości kulturowych i komunikacyjnych, a co za tym idzie, do zmian tożsamościowych (Duszak, 2004, s. 60).

Od przełomu wieków XX i XXI amerykanizacji ulega nie tylko ogólnopolski system językowy. Coraz intensywniej szerzy się ona również na inne sfery naszej narodowej kultury. Wydaje się, iż rozmywanie ich granic poprzez promowanie postaw postmodernistycznych (mody na luz, pospolitości, potoczności, intertekstualności i ludyczności), konsumpcjonizmu i medialności oraz stylu komputerowego stopniowo doprowadzi do deterytorializacji polskiej kultury zarówno w miastach, jak i na wsi (Ożóg, 2009, 2014, s. 31).

W okresie powojennym w tradycyjnej kulturze polskiej wsi, nastawionej na ciągłość, najistotniejszym elementem była międzygeneracyjna transmisja dziedzictwa decydująca o zachowaniu chłopskiej tożsamości. Globalizacja, która objęła także lokalny, wiejski system językowo-kulturowy, rozpropagowała jednak na wsi ideologię konsumpcji. Tradycyjną kulturę ludową zastępuje się więc tzw. ludowością sfolkloryzowaną, przetworzoną i bardzo często wykorzystuje się ją marketingowo do promocji regionu. W konsekwencji od przełomu wieków XX i XXI komercyjna kultura wiejska, nastawiona na teraźniejszość, kieruje się głównie aktualnym interesem ekonomicznym (Kaniewski, 2007, s. 6).

Dyfuzja i mieszanie się wzorów kulturowych oznacza jednak, że globalizacja nie usuwa lokalności. Co więcej, wspierana przez postawy postmodernistyczne powoduje odradzanie się ludowości i regionalności, choć zwykle w wersji nie w pełni zgodnej z tradycją (Kurek, 2018, s. 89).

W polskich miastach i wsiach zacieranie się geograficznych i społecznych granic językowo-kulturowych na skutek oddziaływania kodu ogólnopolskiego 
oraz ekspansywnej kultury Zachodu będzie postępować, ale płynność granic nie eliminuje poczucia odrębności, u której podstaw tkwi rdzeń kultury macierzystej.

\section{BIBLIOGRAFIA}

Bartuś, Z. (2018, styczeń 26). Polska wieś razy dwa: Jedna bogaci się i rośnie, druga starzeje się i wymiera. Dziennik Polski.

Dubisz, S. (2011). O niektórych tendencjach rozwojowych leksyki polszczyzny ogólnej w XXI wieku: Na podstawie danych leksykograficznych. W B. Pędzich \& D. Zdunkiewicz-Jedynak (Red.), Polskie dźwięki, polskie słowa, polska gramatyka: System - teksty norma - kodyfikacja (ss. 239-246). Wydział Polonistyki Uniwersytetu Warszawskiego.

Duszak, A. (2004). Tekst kultury globalnej. W M. Wojtak \& M. Rzeszutko (Red.), W kregu wiernej mowy (ss. 59-67). Wydawnictwo Uniwersytetu Marii Curie-Skłodowskiej.

Fleszar, M. (1978). Geografia ekonomiczna świata. Państwowe Wydawnictwo Ekonomiczne.

Gajda, S. (2007). Język polski wobec tendencji rozwojowych współczesnego świata. W J. Mazur \& M. Rzeszutko-Iwan (Red.), Język polski jako narzędzie komunikacji we współczesnym świecie (ss. 13-20). Wydawnictwo Uniwersytetu Marii Curie-Skłodowskiej.

Gołębiewski, Ł. (2008). Śmierć książki: No future book. Biblioteka Analiz.

Handke, K. (1995). Nazewnictwo i społeczna przestrzeń miasta. W D. Bieńkowska (Red.), Wielkie miasto: Czynniki integrujace i dezintegrujące 2 (ss. 19-27). Wydawnictwo Uniwersytetu Łódzkiego.

Kaniewski, J. (2007). Jaki kanon? Polonistyka, 2007(5), 6-11.

Kopczyńska-Jaworska, B. (1991). Kulturowe zróżnicowanie mieszkańców Łodzi w okresie międzywojennym i po II wojnie światowej. Acta Universitatis Lodziensis: Folia Ethnologica, 1991(5), 5-26.

Kowalikowa, J. (1995). Między tożsamością a integracją: Regionalizmy w aspekcie komunikacyjnym. W D. Bieńkowska (Red.), Wielkie miasto: Czynniki integrujące i dezintegrujące 2 (ss. 70-77). Wydawnictwo Uniwersytetu Łódzkiego.

Kurek, H. (1990). Metodologia socjolingwistycznego badania fonetyki języka mówionego środowisk wiejskich: Na przykładzie kilku wsi Beskidu Niskiego. Wydawnictwo Uniwersytetu Jagiellońskiego.

Kurek, H. (2018). Kultura ludowa przełomu wieków XX i XXI: Tradycja i zmiana. Słowo: Studia językoznawcze, 2018(9), 84-91. https://doi.org/10.15584/slowo.2018.9.08

Kurek, H. (2019). Współczesna polska wieś - pogranicze języków i kultur. Rozprawy Komisji Językowej Łódzkiego Towarzystwa Naukowego, 67, 209-217. https://doi.org/10.26485 /RKJ/2019/67/14

Luchter, B. (2012). Kraków - zarys przemian ekonomiczno-przestrzennych. Wydawnictwo Uniwersytetu Ekonomicznego w Krakowie. 
Mańczak-Wohlfeld, E. (2010). Język polski w dobie globalizacji. W J. S. Gruchała \& H. Kurek (Red.), Silva rerum philologicarum: Studia ofiarowane Profesor Marii Strycharskiej-Brzezinie z okazji Jej jubileuszu (ss. 213-221). Księgarnia Akademicka.

Mańczak-Wohlfeld, E. (2012). The assimilation of English loanwords in Polish and German on the semantic level. W M. Olpińska-Szkiełko, S. Grucza, Z. Berdychowska, \& J. Żmudzki (Red.), Der Mensch und seine Sprache (ss. 428-435). Peter Lang.

Mańczak-Wohlfeld, E. (2013). English loanwords in Polish. Kwartalnik Neofilologiczny, 60, 17-28. Mańczak-Wohlfeld, E., \& Witalisz, A. (2016). The influence of English on Polish morphology. Kwartalnik Neofilologiczny, 63, 421-434.

Markowski, A. (2008). Kultura języka polskiego: Teoria: Zagadnienia leksykalne. Wydawnictwo Naukowe PWN.

Miodunka, W. (2003). Moc języka i jej znaczenie w kontaktach językowych i kulturowych. W J. Bartmiński \& J. Szadura (Red.), Współczesna polszczyzna: Wybór opracowań: T. 2. Warianty języka (ss. 12-16). Wydawnictwo Marii Curie-Skłodowskiej.

Ożóg, K. (2001). Polszczyzna przełomu XX i XXI wieku: Wybrane zagadnienia. Wydawnictwo „Otwarty rozdział”.

Ożóg, K. (2009). Polszczyzna pierwszej dekady XXI w. - próba uchwycenia najważniejszych zjawisk. W B. Dunaj \& M. Rak (Red.), Polszczyzna mówiona i regionalna (ss. 21-39). Księgarnia Akademicka.

Ożóg, K. (2014). Współczesna polszczyzna wobec zmian kulturowych przełomu XX i XXI wieku. W W. Śliwiński, G. Olchowa, \& A. Račákova (Red.), Słowiański dialog kulturowy: Studia leksykalne i gramatyczne (ss. 16-35). Belianum.

Piotrowicz, A., \& Witaszek-Samborska, M. (2016). Globalizacja a współczesna polszczyzna w świadomości studentów. W H. Kurek, M. Święcicka, \& M. Peplińska (Red.), Globalizacja a przemiany języków słowiańskich (ss. 153-168). Wydawnictwo Uniwersytetu Kazimierza Wielkiego.

Rajman, J. (1997). Strefa podmiejska - mechanizm powstawania przekształceń: Nowe problemy badawcze. W B. Domański (Red.), Geografia. Człowiek. Gospodarka: Profesorowi Bronisławowi Kortusowi w 70. rocznice urodzin (ss. 67-73). Instytut Geografii Uniwersytetu Jagiellońskiego.

Sawaniewska-Mochowa, Z., \& Moch, W. (2001). Językowy obraz miasta w tekstach hiphopowych. W M. Białoskórska (Red.), Synchroniczne i diachroniczne aspekty badań polszczyzny 7 (ss. 267-281). Wydawnictwo Naukowe Uniwersytetu Szczecińskiego.

Szymczak, M. (Red.). (1979). Słownik języka polskiego (T. 2). Państwowe Wydawnictwo Naukowe.

Topolińska, Z. (1990). Charakterystyka i dynamika językowych procesów integracyjnych w powojennej Polsce. Socjolingwistyka, 1990(9), 29-35.

Ustawa o urzędowych nazwach miejscowości i obiektów fizjograficznych z dnia 29 sierpnia 2003. (2003). Dziennik Ustaw, 2003(166), poz. 1612.

Witalisz, A. (2016). Przewodnik po anglicyzmach w jezyku polskim. Wydawnictwo JAK.

Zeler, B., \& Żydek-Bednarczuk, U. (2009). Homo communicans w świecie wirtualnym. W A. Kiepasa, M. Sułkowska, \& M. Wołek (Red.), Człowiek a światy wirtualne (ss. 83-91). Wydawnictwo Uniwersytetu Śląskiego. 


\section{Polskie miasta i wsie XXI wieku. Zacieranie się granic, języków i kultur}

Do połowy XX wieku wielkie miasta jako organizmy gospodarcze i zbiorowości charakteryzujące się bardzo zróżnicowaną strukturą zawodową i społeczną ludności, oddzielały od monolitycznej, tradycyjnej wsi nie tylko granice administracyjne, lecz także wyraźne granice językowe i kulturowe. Po II wojnie światowej na skutek różnorodnych procesów społeczno-ekonomicznych, powodujących między innymi wchłanianie przez wielkie miasta okolicznych wsi, zmianom zaczęły też ulegać granice administracyjne. Migracje ze wsi do miast i wzrost poziomu wykształcenia ludności napływowej rozpoczęły w drugiej połowie XX wieku proces zacierania się również granic kulturowych i językowych. Na początku XXI wieku zjawisko unifikacji językowo-kulturowej znacznie przyspieszyła moda na osiedlanie się w podmiejskich wsiach mieszkańców dużych miast. Gwałtowne nasilenie się omawianego procesu nastąpiło jednak przede wszystkim na skutek powszechnej dostępności Internetu. Język angielski i kultura w stylu amerykańskim stały się czynnikami unifikującymi zróżnicowania językowe i kulturowe polskich miast i wsi. W pierwszej ćwierci XXI wieku rozpoczął się więc proces zacierania się granic językowo-kulturowych pomiędzy miastem a wsią, a także wirtualnych granic pomiędzy rodzimą kulturą polską a obcą kulturą świata zachodniego.

Słowa kluczowe: globalizacja, język, kultura, polskie miasta, polskie wsie

\section{Polish Cities and Villages in the 21st Century: Blurring of the Borders, Languages and Cultures}

Up to the middle of the $20^{\text {th }}$ century, big cities, as economic units and communities that were characterized by the very varied professional and social structure of their inhabitants, marked not only administrative borders but also clear linguistic and cultural borders for the traditional monolithic village. After the Second World War, due to various socio-economic processes which resulted in big cities absorbing the surrounding villages, the administrative borders also started to change. Migrations from villages to cities and improved education began the process of blurring cultural and linguistic borders in the $20^{\text {th }}$ century. At the beginning of the $21^{\text {st }}$ century, the phenomenon of linguistic-cultural unification was facilitated by the trend of inhabitants of big cities starting to move to suburban villages. However, the rapid intensification of this phenomenon was mainly influenced by the common availability of the internet. The English language and the American style of culture became the factors that unified the linguistic and cultural differences between Polish cities and villages. The first 
quarter of the $21^{\text {st }}$ century marked the beginning of the process of blurring not only the cultural differences between the city and the village, but also the virtual borders between Polish culture and the foreign culture of the Western world.

Keywords: globalization, language, culture, Polish cities, Polish villages

\section{Notka o autorce}

Halina Kurek (halina.kurek@uj.edu.pl) - prof. dr hab., badaczka przemian polszczyzny miast i wsi w XX i XXI wieku w ujęciu socjolingwistycznym i kulturowym, kierownik Katedry Lingwistyki Kulturowej i Socjolingwistyki Wydziału Polonistyki Uniwersytetu Jagiellońskiego, przewodnicząca Rady Dyscypliny Językoznawstwo na UJ, a także Komisji Socjolingwistyki afiliowanej przy Międzynarodowym Komitecie Slawistów oraz krakowskiego Oddziału Komisji Językoznawstwa Polskiej Akademii Nauk, członek Komitetu Językoznawstwa PAN oraz rad naukowych „Socjolingwistyki” i „LingVariów”. Opublikowała między innymi prace: Metodologia socjolingwistycznego badania fonetyki języka mówionego środowisk wiejskich (na przykładzie kilku wsi Beskidu Niskiego) (Kraków 1990), Przemiany językowe wsi regionu krośnieńskiego (Kraków 1995), Przemiany leksyki gwarowej na Podkarpaciu (Kraków 2003), Polszczyzna mówiona inteligencji (Kraków 2008) oraz Przemiany fleksji nominalnej w polszczyźnie przełomu wieków XX i XXI (na przykładzie imion i nazwisk oraz appellativów) (Kraków 2019).

Halina Kurek (halina.kurek@uj.edu.pl) - PhD (with 'habilitation'), researcher of changes in the Polish language in cities and villages in the $19^{\text {th }}$ and $20^{\text {th }}$ centuries in the sociolinguistic and cultural perspective; director of the Department of Cultural Linguistics and Sociolinguistics of the Faculty of Polish Studies at Jagiellonian University; president of the Scientific Council of Linguistics at Jagiellonian University; president of the Sociolinguistics Commission, affiliated at the International Committee of Slavists; president of Cracow Department of the Linguistics Commission of the Polish Academy of Sciences (PAN); member of the Linguistics Committee of PAN; member of scientific councils of journals: "Sociolinguistics" and "LingVaria". Author of the follow- 
ing publications: Metodologia socjolingwistycznego badania fonetyki języka mówionego środowisk wiejskich (na przykładzie kilku wsi Beskidu Niskiego) [Methodology of the Sociolinguistic Analysis of the Phonetics of Spoken Language of Rural Communities (Based on Several Villages in Low Beskids)] (Cracow, 1990), Przemiany językowe wsi regionu krośnieńskiego [Linguistic Changes in Villages in the Area of Krosno] (Cracow, 1995), Przemiany leksyki gwarowej na Podkarpaciu [Changes in Dialectal Lexis in Podkarpacie] (Cracow, 2003), Polszczyzna mówiona inteligencji [Spoken Polish of Intelligentsia] (Cracow, 2008), and Przemiany fleksji nominalnej w polszczyźnie przełomu wieków XX i XXI (na przykładzie imion i nazwisk oraz appellativów) [Changes in Nominal Inflection in the Polish Language at the Turn of the $20^{\text {th }}$ and $21^{\text {st }}$ Centuries (Based on First Names and Surnames, as well as Appellatives)] (Cracow, 2019). 